\title{
Comparative Study of Online Collaborative Tools for Identification of Effective Tool for Marketing of Products
}

\author{
Anwesha Sinha \\ JK Lakshmipat University \\ India
}

\author{
S. Taruna, $\mathrm{PhD}$ \\ JK Lakshmipat University \\ India
}

\begin{abstract}
Collaboration literally means "working together"-colaboring, not just co-talking. Collaboration tools cannot just be about better knowledge sharing; they need to improve the speed and effectiveness of people's efforts, getting things done in a timely and effective manner, execute tasks, communications, tracks progress, and achieves goals, no matter where the team members are located. This makes suitable for decentralized companies operating in more than one location. The research analysis was to be done by comparing all the available tool. This project has been aimed to identify the most suitable collaborative tool for the company to use both economically \& efficiently. This included advanced research on KPIs, dashboard, normalization, comparison, ease of use.
\end{abstract}

\section{Keywords}

KPI, Collaborative Tools, Trello, Wrike, MeisterTask, ProjectPlace

\section{INTRODUCTION}

There is an urgent need of the company or an organization to be more productive and efficient by project management. To track and manage a large number of complex projects, collaboration not just co-talking, video conferencing, contact management to tag and maintain contact details related to ongoing projects, sharable whiteboard for teams to express ideas visually in synchronous work sessions, file versioning to help track multiple versions of a file so that one can reclaim a previous version if something goes wrong, edit and re-edit important files, synchronous chat management Real-time chat that can be used by multiple participants and the conversations can be stored for future reference. The companies are flooded with projects \& data which are required to be managed. Moreover, there is nothing prevalent in the company to manage their workflow, load burden of the employees, to view the top performers of the projects, time tracking of each project, statistic and overall projects handled by each employee. The company or an organization have various departments and the employees of different departments are needed to collaborate on a platform for discussing their ideas, workflow \& projects at any time without their physical presence.

\section{LITERATURE REVIEW}

Based on Secondary Research like Google ratings, no of downloads, some basic protocols of the companies' requirement, a list of collaborative tools were analyzed which are as under:

\section{- TRELLO \\ - $\quad$ MEISTERTASK \\ - WRIKE}

- PROJECTPLACE

- $\mathrm{ZOHO}$

- DAPULSE

- YAMMER

- MICROSOFT ENTERPRISE PROJECT MANAGEMENT

\subsection{Trello}

Trello offers many important PM \& collaboration benefits. First and foremost, Trello is easy to use. The card system contains all possible nuggets of information about a project. Trello is available as an app on iPhone and Android, so it is easy to access even while mobile. The web version supports most browsers and can also be accessed whether one is using Apple or Android phones or tablets.

\subsection{MeisterTask}

It offers features as Connectivity through other apps like attachment with google drive, box, dropbox, MindMiester, local files from pc. Facility of tags, checklists, statistics in pro meister task adds to the advantage. Additional features for better project management like time tracking, task relationships, could associate with slack, GitHub, office, Zendesk. It can easily print the project which includes open, in progress, done or any other section as per made for the project.

\subsection{Wrike}

User-friendly navigation, excellent security measures to ensure that no other than authorized personnel can access the information and other files stored in the online database are the added benefit of Wrike. Its special features are 3-Plane Project View, Excellent Analytics, TLS 256-bit algorithm in CBC mode.

\subsection{PROJECTPLACE}

Document Management with Reviews, Burn-Up Charts, Developer API, Real Time Collaboration, Online Meetings are the special features of ProjectPlace.

\section{$2.5 \mathrm{ZOHO}$}

Dropbox Integration, Hourly tasks, subtasks, GitHub Integration, Document Management are the highlights one can find in Zoho.

\subsection{DAPULSE}

Personal, Public Boards, email notifications, progress display, sharable board are the special attractions of Dapulse.

\subsection{YAMMER}

Yammer was acquired by Microsoft and they've supported the 
tool It has a very intelligent engine behind it, which surfaces content that it thinks might find relevance based on previous interactions. It makes communication smoother than any other collaborative tools. It is basically for overall company which may include polling, praising, less for project management, document sharing done on wider bases so it's a better platform for document sharing.

\subsection{MICROSOFT EPM}

It holds all the basic features of collaborative tools for the smooth environment.

\section{Methodology Adopted}

The work required Key Performance Indicators to compare among the tools which are as: Identify the business problem, refine the solution, track the progress, improved customer satisfaction, manage users \& assign modules, team management, problem solving, decision making, time management, collaborative discussions, blogging, mobility, analytics, resource management, security, integration with other apps, user friendly, task prioritization, important data at a glance, sharable whiteboard, file versioning, project management, export as CSV, multi-language support, cost, onboarding \& trainings, online meetings, voting feature. Further for evaluation purpose different weightages are assigned to different KPI's and evaluated for their comparative evaluation. Based on the evaluation further evaluation to be considered on among top rated collaborative tools to find out the most effective one for the corporation.

To understand the weightage of the KPI's, a survey was adopted wherein questionnaires pertaining to the identification of the functionalities were to be identified. This was done via survey sheet online and in offline mode.

\section{Tools Funnel}

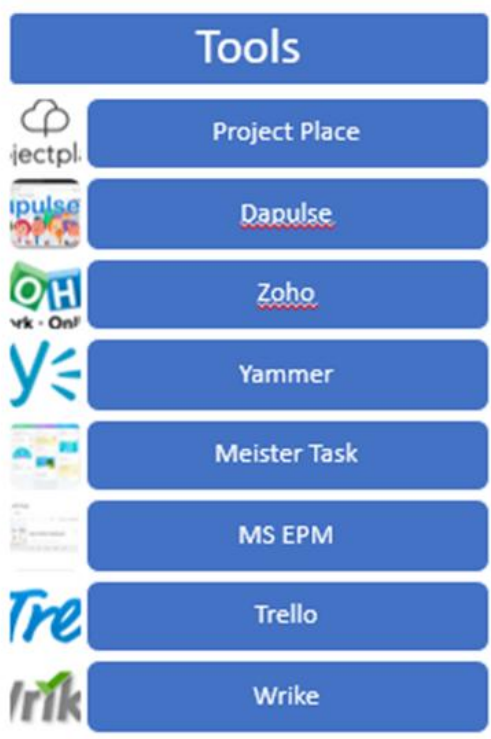

Figure I: Tools Funnel

\subsection{Key Features of Collaborative Tools}

The key features which is essential in a collaborative tool are:

a) Project management - This feature helps to track and manage many complex projects.

b) Contact management - The ability to tag and maintain contact details related to ongoing projects.

c) Synchronous chat - Real-time chat that can be used by multiple participants and the conversations can be stored for future reference.

d) Video conferencing - The value of the collaboration tool increases if it offers an integrated video conferencing feature.

e) Sharable whiteboard - Whiteboards are useful for teams express ideas visually in synchronous work sessions.

f) File versioning - Your team may edit and re-edit important files. File versioning helps you track multiple versions of a file so that you can reclaim a previous version if something goes wrong.

g) Integrations with other Apps: The collaboration tools should be able to smoothly integrate with the other business systems and apps you use. This can save you lots of time and improve productivity.

Based on the above-mentioned Collaborative Tools and their key features, the tool funnel was prepared. Further the survey was conducted.

Through the survey weightage was decided for the different KPI's after normalization. KPI is the key performance indicators which here acted as the parameters or the deciding factors for the comparison of the different tools based on the peoples' requirements. 


\begin{tabular}{|c|c|}
\hline & Weightage (\%) \\
\hline \multicolumn{2}{|l|}{ KPI } \\
\hline Identify the business problem & 35 \\
\hline Refine the solution & 20 \\
\hline Track the progress & 40 \\
\hline Improved customer satisfaction & 85 \\
\hline Manage users \& assign modules & 25 \\
\hline Team Management & 30 \\
\hline Problem Solving & 75 \\
\hline Decision Making & 80 \\
\hline Time Management & 60 \\
\hline Collaborative Discussions & 50 \\
\hline Blogging & 20 \\
\hline Mobility & 30 \\
\hline Analytics & 80 \\
\hline Security & 85 \\
\hline Integration with other apps & 60 \\
\hline User friendly & so \\
\hline Task prioritization & 45 \\
\hline Notifications & 30 \\
\hline Sharable Whiteboard & 30 \\
\hline File Versioning & 40 \\
\hline Project Management & 95 \\
\hline Export as CSV & 20 \\
\hline Multi language support & 30 \\
\hline Pricing Type & 60 \\
\hline Cost & 50 \\
\hline Onboarding \& Trainings & 40 \\
\hline Online Meetings & 60 \\
\hline voting feature & 25 \\
\hline Data Storage & 80 \\
\hline No of downloads & 30 \\
\hline Manage your profile & 40 \\
\hline Attachments Supported & 70 \\
\hline extra feature & 75 \\
\hline customisation & 75 \\
\hline \multicolumn{2}{|l|}{ you tube link video } \\
\hline Backup & 80 \\
\hline Device Supported & 80 \\
\hline
\end{tabular}

Figure II: Key Performance Indicators \& Weightage

\section{OBSERVATIONS}

Based on the above results total score was calculated for each tool. Graph was plotted for various KPI and weightage was observed. The top 3 tools were ProjectPlace, Wrike \& MeisterTask. They were used as their pro versions for a couple of days and their additional benefits like integration with other apps were also judged. Further the security, data privacy policy was rigorously observed. The observation with color labels is illustrated below. Wrike which is represented with green label overpowers the other tools in the chart which is between the weightage and their KPI for the collaborative tools. 


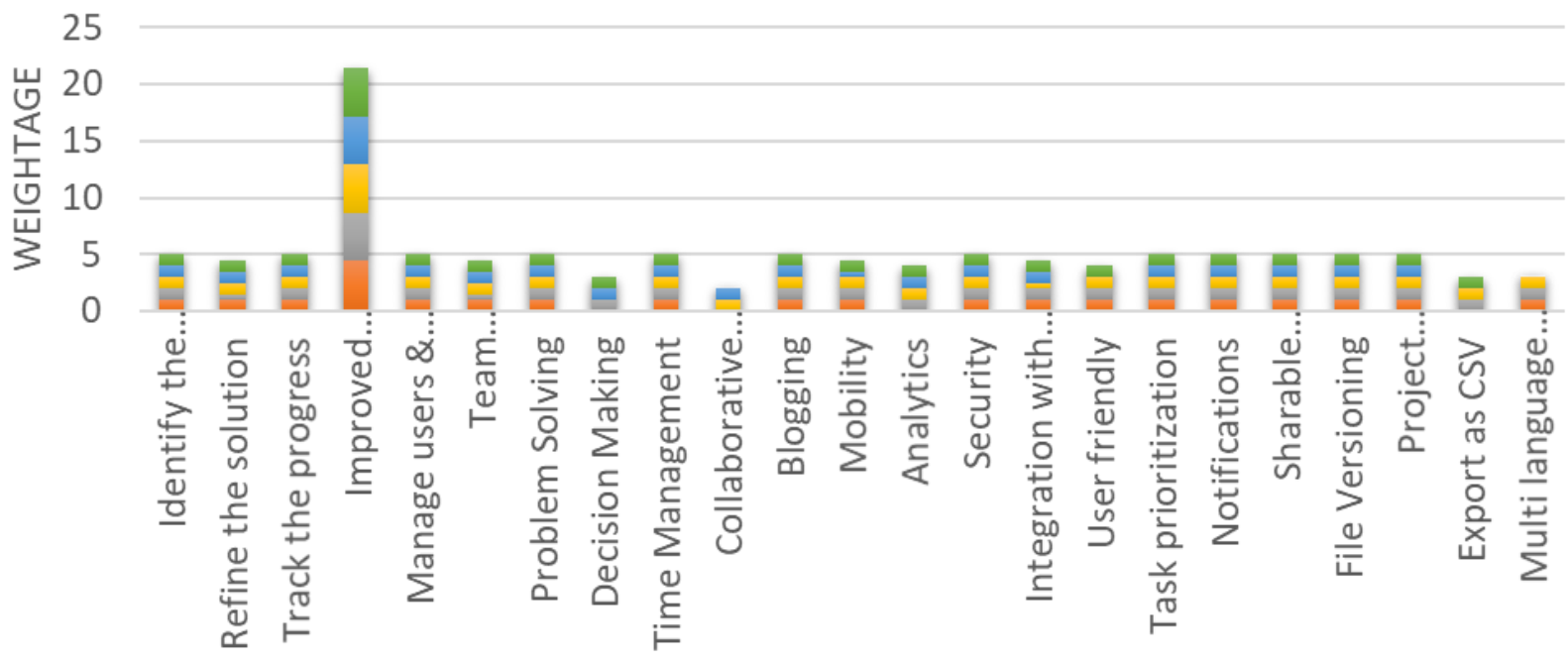

$\mathrm{KPI}$

Trello Meister Task $\square$ ProjectPlace $\square$ Zoho $\square$ Wrike

Figure III: Bar Chart (X Axis-KPI \& Y Axis-Weightage)

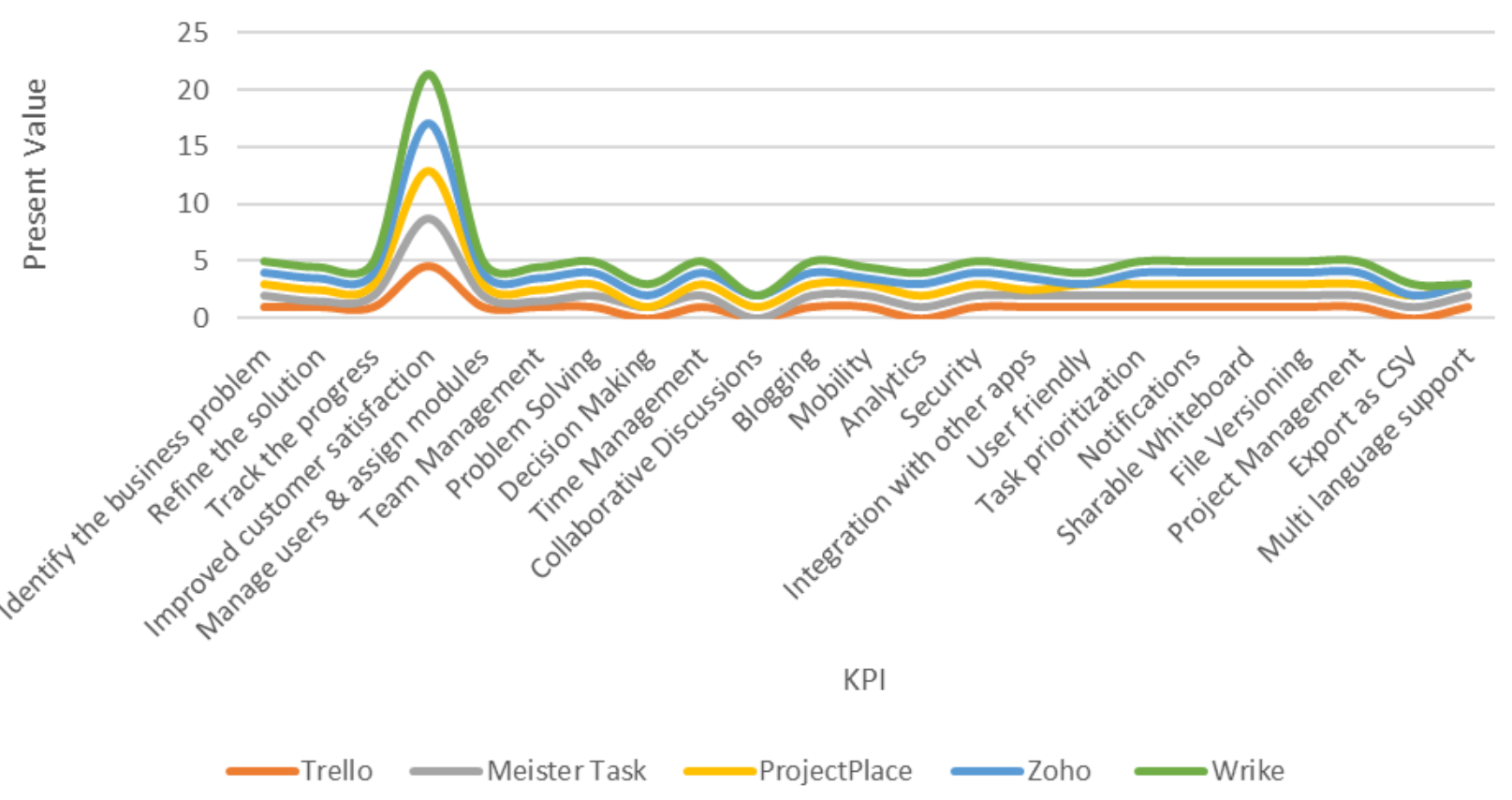

Figure IV: Comparative Graph (X Axis-KPI \& Y Axis-Weightage) 


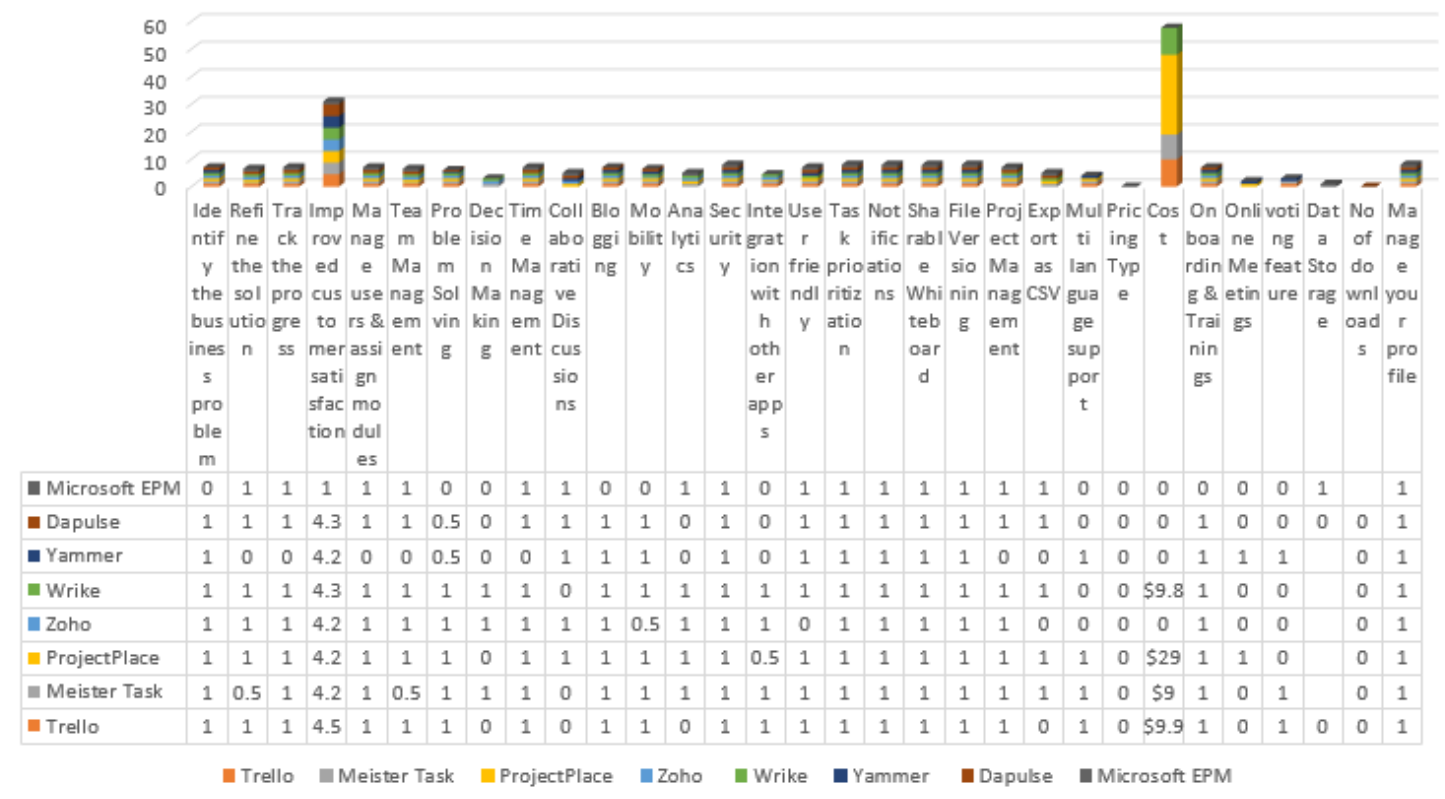

Figure V: KPI versus Collaborative Tools

\section{CONCLUSION}

Executives are right to expect more from the new wave of collaborative technologies. Adding social networking and crowdsourcing to collaborative tools provides new potential to improve organizational agility, increase productivity, aid decision making and spark idea generation. Rather than accept just modest improvements from these technologies, executives should aim high and pursue the greater gains that can come by embedding collaboration into specific processes, incentivizing collaborative behaviors and thinking more strategically about these important technologies. WRIKE has most of the KPI present in it and so it should be preferred over other online collaborative tools. Adding social networking and crowd sourcing to collaborative tools provides new potential to improve organizational agility, increase productivity, aid decision making and spark idea generation. Rather than accept just modest improvements from these technologies, executives should aim high and pursue the greater gains that can come by embedding collaboration into specific processes, collaborative behaviors and thinking more strategically about these important technologies

\section{SUMMARY}

The work on Collaborative Tool is efficient for the company $\&$ organization. Finding the best suitable tool for the company is both feasible and economical. It included a research, survey, statics to find out the best one and emerged out to be Wrike.

\section{REFERENCES}

[1] Van Eemeren, Frans H., Rob Grootendorst, and Frans Hendrik Eemeren. A systematic theory of argumentation: The pragma-dialectical approach. Vol. 14. Cambridge University Press, 2004.

[2] Osborne, Jonathan, Sibel Erduran, and Shirley Simon. "Enhancing the quality of argumentation in school science." Journal of research in science teaching 41.10 (2004): 994-1020.
[3] Taylor, James R., and Elizabeth J. Van Every. The emergent organization: Communication as its site and surface. Routledge, 1999.

[4] Taylor, James R., and Elizabeth J. Van Every. The emergent organization: Communication as its site and surface. Routledge, 1999.

[5] Duschl, Richard. "Science education in three-part harmony: Balancing conceptual, epistemic, and social learning goals." Review of research in education 32.1 (2008): 268-291.

[6] Berland, Leema Kuhn, and Brian J. Reiser. "Making sense of argumentation and explanation." Science Education 93.1 (2009): 26-55.

[7] Erduran, Sibel, and María Pilar Jiménez-Aleixandre. "Argumentation in science education." Perspectives from classroom-Based Research. Dordre-cht: Springer (2008).

[8] Von Aufschnaiter, Claudia, et al. "Arguing to learn and learning to argue: Case studies of how students' argumentation relates to their scientific knowledge." Journal of Research in Science Teaching: The Official Journal of the National Association for Research in Science Teaching 45.1 (2008): 101-131.

[9] Sadler, Troy D., Sasha A. Barab, and Brianna Scott. "What do students gain by engaging in socioscientific inquiry?." Research in Science Education 37.4 (2007): 371-3

[10] Ford, Michael J., and Ellice A. Forman. "Chapter 1: Redefining disciplinary learning in classroom contexts." Review of research in education 30.1 (2006): $1-32$.

[11] Ford, Michael J., and Ellice A. Forman. "Chapter 1: Redefining disciplinary learning in classroom contexts." Review of research in education 30.1 (2006): $1-32$. 